\title{
Research on Organizational Resilience of Railway Transport Industry Under COVID-19 Epidemic
}

\author{
Yuqing Zhang*, Kunting Pan \\ School of Economics and Management, East China Jiaotong University, Nanchang, China. \\ ${ }^{*}$ Corresponding author. Email: 1029299164@qq. com
}

\begin{abstract}
CoVID-19 epidemic has brought a great impact to China's railway transportation industry. How to respond quickly to make it return to the original state is a problem worth thinking about. Organizational resilience refers to the prevention before the crisis and the rapid response after the crisis to restore the original state level and seek opportunities for organizational development. Improving the organizational resilience of China's railway transportation industry to better deal with COVID-19 epidemic is the focus of this paper. The main ways of improvement include maintaining a keen awareness of the environment, improving the organizational resilience of employees, creating an environment of trust, appropriately organizing resource redundancy, and building an organizational structure that combines rigidity and flexibility. Even if coVID-19 is under control, there will be crises like this in the future, so it is important for organizations to improve their resilience, and the rail industry needs to be prepared for a public health crisis.
\end{abstract}

Keywords: COVID-19 Epidemic, Railway Transportation, Organizational Resilience, Crisis Response.

\section{INTRODUCTION}

In early 2020, the COVID-19 outbreak swept the world. During the epidemic, China's economy was almost put on hold. On January 30, 2020, WHO listed novel Coronavirus outbreak as a public health emergency of international concern. The railway transportation industry plays an important role in China's economic and social development and is the main artery of China's national economic development and The COVID-19 epidemic has had a significant impact on economic operations [1,2]. During the epidemic period, the railway transport industry, on the one hand, bears the economic losses caused by the decrease of passenger volume, and on the other hand, actively cooperates with the government in epidemic prevention and transportation, and undertakes the important tasks of transporting medical personnel and medical supplies. Sudden crisis events such as COVID19 often make an organization suffer from adversity and pose a great challenge to the organization. In complex environment, the strength of organizational resilience will affect the development of organizations. The resilience of different organizations is also different. Organizations with strong resilience are more likely to learn and develop in the face of adversity.

\section{THE PLIGHT OF THE RAILWAY TRANSPORT INDUSTRY UNDER THE COVID-19 EPIDEMIC}

In the epidemic prevention and control work, the railway transport industry is under great pressure. While giving full play to its supporting role, its own development is also being severely impacted. The 40day 2020 Spring Festival travel rush ends on Feb 18 . This year's Spring Festival travel rush has seen 210 million passenger trips, down 47. 3 percent year-onyear, and the passenger volume has been greatly impacted. Due to the impact of the epidemic, especially after the closure of Wuhan city, the number of tourists dropped off a cliff. The daily passenger traffic will drop to less than $10 \%$ in the same period of 2019. Assuming that the number of railway passengers such as China Railway Group is expected to reach 440 million during the Spring Festival travel rush, and the per capita ticket spending is calculated at 100 yuan, China Railway Group alone will lose 23 billion yuan of passenger revenue during the 40-day Spring Festival travel rush. See Figure 1 for details. At the same time, in the early stage of the epidemic, the policy of free ticket refund was implemented to extend the period of refund, so as to protect the economic interests of passengers to the 
maximum extent. From January 21, solstice, February 18,2020 , a total of 11.8 billion tickets were refunded for free by the national railways, resulting in huge economic losses. However, in the later stage, the decentralized ticketing strategy was implemented, i. e., no no-seat tickets were purchased, and alternate seat tickets were implemented to control the passenger load rate at about $50 \%$, and the passenger volume also grew slowly.

In addition, the railway transportation industry is also responsible for transporting medical supplies and transporting medical personnel [3]. At the same time, in order to ensure safety, it is necessary to take body temperature one by one in and out of the stations, carry out acute disinfection in the activity areas for passengers with fever, and carry out comprehensive terminal disinfection after the train arrives at the terminal point. The work is more complicated and onerous than usual. As a place with large population flow, elimination work is particularly heavy. Even in closed areas, passenger volume is very small circumstances, all departments still have to organize personnel to guard, daily elimination. In addition, working in places with large population flow also increases the risk of infection, which inevitably brings anxiety and other emotions to employees. Diversified business is also affected to some extent.

There are many diversified business design businesses, and some of them rely on passenger transportation, such as ticket booking, ticket delivery and tourism services. In the early stage, in order to welcome the Spring Festival holiday, the general enterprises will arrange the product inventory for nearly one or two months in advance. Due to the "lockdown" effect of the epidemic, the freight volume will be reduced to a relatively limited extent due to the production reduction. Secondly, the railway freight volume is large, the route is special, although the "closure of the city", control the flow of people, but the impact on the railway freight is not big. Thirdly, affected by the epidemic, many medical supplies such as epidemic prevention and sanitation supplies need to be transported by railway, which will lead to the increase of railway traffic. According to the data, from January to February 2020, 670 million tons of goods were sent by China's railways, up 0 . 6 percent year-on-year. However, in the long run, the resumption rate is low, the upstream raw material demand and the downstream product transport demand will directly lead to the reduction of railway freight volume, the demand for rail freight may be reduced. Organizational resilience can help organizations better respond to crisis situations and rapidly return to pre-crisis adaptation and development capabilities.

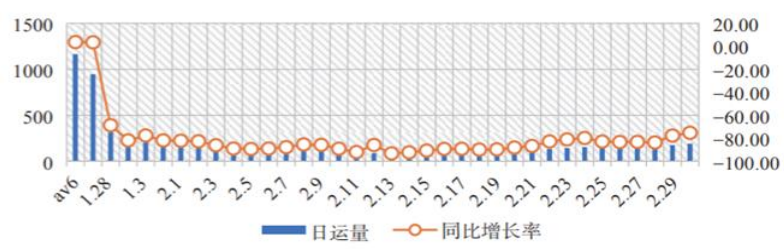

Figure 1 Daily Railway Passenger Volume from January 10 to March 1, 2020 (unit: 10, 000, \%).

\section{THE CONNOTATION OF ORGANIZATIONAL RESILIENCE}

The concept of stress resistance originated in physics and engineering. It refers to the ability of an object to return to its original state without breaking when it is bent by external forces or other deformations [4]. Later, it became the research object of psychology, sociology, management and other fields. Resilience involves individuals, communities, organizations and other levels. The research on individual resilience and community resilience has a long history, and scholars have begun to study it earlier, while the research on organizational resilience is relatively weak. Individual resilience is defined as an individual's ability to successfully adapt to and work actively after facing a high-risk situation, persistent stress or trauma (Egeland, 1993) [5]. Community resilience refers to the ability of community members to take meaningful, deliberate and collective actions to remedy the impact caused by problems, including environmental interpretation, intervention and action (Pfefferbaum, 2005) [6]. Community resilience stems from four kinds of adaptability: economic development, social capital, information and communication, and organizational ability (Norris, 2008) [7].

At present, the definition of organizational resilience has not been unified. Organizational resilience can be divided into pre-crisis prevention and post-crisis recovery according to the period of action, and most scholars' research focuses on post-crisis $[8,9]$. There are two main perspectives on what organizational resilience is. Some scholars regard organizational resilience as just a kind of resilience of an organization -- in a complex and changeable environment, when an organization suffers sudden setbacks, it can quickly recover to the ability before difficulties in the face of huge pressure and difficulties(Balu, 2001;Dutton, Frost, Worline, Lilius, \&Kanov, 2002; Gittell, Cameron, Lim, \&Rivas, 2006; Horne \& Orr, 1997; Mallak, 1998b; Robb, 2000; Rudolph \& Repenning, 2002; Sutcliffe \& Vogus, 2003, Mei Ye, 2012) [10-15]. This definition is more similar to a physical definition of resilience - the ability of an object to regain its original shape and character after being bent or struck. This definition places more emphasis on problem-solving strategies and the ability to quickly return to original performance levels. Faced with the sudden crisis, the organization actively seeks 
for countermeasures, and tries its best to restore the organization to the normal state before the crisis, so as to ensure the expected organizational performance [17]. In the second perspective, organizational resilience is not only the ability to quickly recover to the original state in the face of sudden crisis, but also the ability to make use of the opportunities brought by the sudden crisis to make the organization develop (Coutu, 2002; Freeman, Hirschhorn, \&Maltz, 2004; Guidimann, 2002; Jamrog et al., 2006; Layne, 2001; Lengnick - Hall \& Beck, 2005; Weick, 1988) [18-21]. Organizational resilience is developed by being able to take advantage of unexpected challenges and changes. Organizational resilience is seen as enabling organizations to use their resources and capabilities not only to return to the status quo, but also to capitalize on opportunities to build new successes. (Cynthia, 2011) [22]. In the second view, organizational resilience is defined as the ability of organizations to effectively absorb, respond to specific situations, and ultimately carry out transformative activities to take advantage of destructive accidents that may threaten the survival of organizations. (Coutu, 2002; Freeman, Maltz, \& Hirschhorn, 2003; Guidimann, 2002; Hamel \& Valikangas, 2003; Jamrog et al., 2006; LengnickHall \& Beck, 2005, 2009; McCann, 2004) [15, $20,23,24,26]$.

Different scholars have put forward different views on the composition of organizational resilience. Organizational resilience should include flexibility, adaptability, agility, etc., but singleness does not work (Ghemawat \& Del Sol, 1998; McCann, 2004; Chakravarthy, 1982) [25-27]. Other scholars have summarized three key elements of organizational resilience, including (1) foresight (the ability to predict adverse events that might occur), (2) coping (the ability to prevent adverse events from worsening), and (3) recovery (the ability to recover from a bad situation). Each of these elements corresponds to an individual, a team, and an organization. Other studies have suggested that specific cognitive ability, behavioural characteristics and situational conditions are the three essential elements of organizational resilience (Cynthia, 2011) [22].

Here, define organizational resilience as an organization's ability to prevent and perceive crises before they occur, and its ability to improvise and use resources to recover from crises and gain organizational development after they occur. First of all, closely related to the organization's prevention and perception of the crisis is the organization's expectation of the crisis, including the leaders' awareness of the crisis, the introspection of the current situation, the collection, processing and detection of environmental information, etc. The leader of the organization should have a strong sense of crisis; Organizations should constantly reflect on the status quo, not get bogged down in experience because of past successes, nor blindly adopt new strategies due to overconfidence, so that they are in the whirlpool of crisis. The organization should predict the future with a positive and objective attitude, and establish an intelligence system to collect and process internal and external environmental information, so as to more sensitively catch the signal of crisis and prevent it from occurring.

Moreover, even if the organization is aware of the crisis, it is impossible to predict all the details of the crisis situation. Therefore, when an organization is faced with a real crisis, one of the keys to recover from the crisis and even improve its ability is the organization's improvisation in the crisis situation. Organizational improvisation is a process in which an organization actively accepts all kinds of feedback information in order to adapt to environmental changes. Through continuous optimization and coordination of internal structure, it promotes the qualitative leap and improvement of overall capabilities and generates new and higher-level capabilities that the original system does not have [28]. In essence, organizational improvisation is also a learning process, which shows that the organization and its members make use of necessary resources to make certain "improvisation" according to the changes of the environment. Therefore, to achieve good results, organizational improvisation also depends on all available material, knowledge, emotion and other social resources in the specific context.

The crisis situation is unpredictable and rapidly changing, so the organization and its members should be able to get rid of the constraints of experience and ability formed in the normal situation, and make "improvisational" response in the face of unexpected and unknown situation. The crisis and post-crisis situation are not completely under the control of the organization. The organization can only try to understand the development of the situation and adjust its response measures at any time. The creative way in which an organization and its members deal with difficult problems in a crisis situation is improvisation, which not only helps the organization get out of trouble, but may also lead to the discovery of new knowledge that improves organizational capabilities. In addition, some studies have pointed out that the improvement of individual resilience will lead to the improvement of the resilience of the whole organization. Although organizations with stress-resistant individuals may not necessarily be stress-resistant, organizations without them will not be stress-resistant. Only when individuals in an organization actively solve problems in the face of adversity and improve their own ability in solving problems, can good organizational improvisation be achieved and organizational resilience be improved. To improve resilience, organizations also need to create an environment of trust. Only when organizations fully trust employees and properly empower them, can they 
make more flexible use of various resources, improvise and solve problems in a crisis. Employees who are trusted by the organization will understand the meaning of their work and actively seek for the echo of their own values and organizational culture. Organization's trust in employees will bring employees' trust in the organization. Employees trust the organization's ability to deal with difficult problems in crisis situations and actively report to the organization the phenomena and problems they have observed on the front line. Organizational improvisation requires teamwork among employees and is rooted in the atmosphere of trust between employees. In addition, internal distrust is likely to become a new crisis for the organization to face.

The construction of rigid and flexible organizational structure is also conducive to the improvement of organizational resilience. The traditional organizational structure is pyramidal and rigid, with more power concentrated at the top. When an enterprise is in a stable external environment, rigid organizational structure and specialized division of labor will bring efficiency to the organization. But once faced with a crisis situation, the flexible organizational structure will be more suitable. The different environment determines the change of organizational structure. The flexible organizational structure enables the organization to make more adaptive adjustment to the continuity of the external environment and supports the organization's improvisational behaviour under the crisis situation. Flexible organizational structure is suitable for dynamic and complex external environment. Previous studies have shown that maintaining appropriate resource redundancy is also the resource and structural basis for the formation of organizational resilience (Luo Dongxia, 2011) [29]. Moderate resource redundancy enables the organization to quickly use resources and quickly return to the original state in the face of adversity. Excessive redundancy of resources will reduce their utilization efficiency, and excessive stress will reduce organizational resilience. Below, we will take the railway industry during the COVID-19 epidemic as an example to specifically analyze strategies to improve organizational resilience.

\section{STRATEGIES ON THE DEVELOPMENT OF THE ORGANIZATIONAL RESILIENCE OF TRANSPORTATION INDUSTRY ORGANIZATIONS}

\section{1 Keep a Keen Awareness of Your Environment at All Times}

Organizational resilience includes the ability to perceive crises and take appropriate preventive measures. Maintaining a keen perception of the changes in the environment can, on the one hand, prevent the enterprise from falling into a crisis; on the other hand, even if the enterprise falls into a crisis, it can be fully prepared in terms of resources and capabilities. To remain environmentally sensitive, organizations need a system of information gathering and detection. The outbreak has had a major impact on the organization, but it is not easy to predict its occurrence. The organization can always pay attention to news trends. When a single patient appears in the news report, it should arouse vigilance, strengthen the monitoring of the people leaving The Han People, appropriately increase the preparation of epidemic prevention materials such as masks, thermometers and disinfectants, and tell employees to pay attention to personal protection. All units should also pay close attention to the epidemic situation in their localities, make reasonable prediction of the future epidemic situation according to the current epidemic situation, and transmit the prediction to all departments, so as to make various preparations in advance, and provide psychological counselling and psychological preparation for employees, so as to make connections with local medical and health resources in advance. In the early stage of the epidemic, passenger traffic was greatly reduced, medical supplies were in short supply, and personnel were idle. Therefore, the organization should always pay attention to the employment demand and reasonably allocate employees, such as encouraging idle employees to participate in the production of masks and other materials.

\section{2 Improve Employees' Psychological Resilience}

Studies have shown that individual resilience can be improved. Individual resilience can make individuals more sensitive to environmental changes and respond to them quickly, which can also improve employees' confidence. The improvement of individual resilience can improve organizational resilience. Although individual resilience is not a sufficient condition for organizational resilience, it is a necessary condition. Only when individuals in the organization can actively solve problems in the face of crisis, the crisis can be readily solved. Individual resilience is the individual psychological characteristics, can be developed through training. Ascending individual art force mainly has the following several ways: one is the source control and organization in recruiting talent can increase psychological art force survey of the content, for railway transportation industry, some work is more special, such as the crew on the rail sometimes need to work at night, every road maintenance staff work time can also be black and white and reverse, plus huge customer base, facing the emergent problems more, so to strengthen the railway transport industry employees' psychological compressive ability measurement; Second, psychological training, regularly hired 
psychological experts to carry out lectures, teach the stress relief, improve psychological resilience and other skills; Three is actively guide employee sentiment, the outbreak came, employees face has never faced a major crisis, emotions can fluctuate, around the "city", such as residents coming out of the case, the railway workers will still need to stick to jobs, combined with early outbreak is not nearly large population flow to detect when happened to the Spring Festival, had contact with a lot of people, not have worry, anxiety, organization should guide employees positive emotions, comfort, ease; Four is a leader should make a good demonstration, in the face of the outbreak, leaders need to calm, calm, actively seek countermeasures, such as deployment good sanitizers work, reasonable arrangement good staffing, when material, reasonable plan materials used, show their own art force, to subordinate infection, provide a good learning model.

\section{3 Create an Environment of Trust}

Trust includes the trust of the organization to the employees, the trust of the employees to the organization and the trust between employees. To improve resilience, organizations need to create an environment of trust. Only when organizations fully trust employees and properly empower them can they make more flexible use of resources, improvise and solve problems in a crisis. The organization's trust in employees will also bring employees' trust in the organization. Employees trust the organization's ability to deal with difficult problems in crisis situations and actively report to the organization the phenomena and problems they have observed on the front line. During the epidemic, the trusted organizational environment makes employees willing to actively report what they have seen and heard at the front line, and report the prediction accordingly. They are also willing to tell the symptoms they have shown and not worry about isolation, because they believe that the organization will not give them up. The trusting environment also allows employees to make bold guesses about passengers' physical conditions, report them timely and take measures. At ordinary times, the organization should pay attention to create a trusting organizational atmosphere, convey a good organizational culture, encourage employees to be bold in some things, and the leader should be close to employees and guide them patiently.

\section{4 Appropriately Maintain the Redundancy of Organizational Resources}

Organizational resource redundancy can provide resources guarantee for the organization to quickly respond to sudden crisis. Excessive organizational resource redundancy will bring great cost to the organization, so the organization should maintain appropriate resource redundancy. During the epidemic, proper redundancy of medical and epidemic prevention materials can ensure the supply of medical supplies for a period of time during the epidemic, ensure the safety of employees, and prepare disinfectant and other disinfectant tools in advance, which can also provide a good material basis for the epidemic prevention work. In addition to material redundancy, appropriate redundancy in personnel can also improve organizational resilience. Psychological experts can carry out psychological counseling for employees during the epidemic, so as to relieve their anxiety and anxiety. Logistics personnel can effectively support a large number of elimination efforts between outbreaks. Reserve personnel with certain medical basis can better assist passengers to judge the illness. Moderate resource redundancy provides necessary material and human resources for organizational improvisation, which can improve organizational resilience.

\section{5 Build a Rigid and Flexible Organizational Structure}

The main body of the rigid and flexible organization structure is still a pyramid structure, but the pyramid structure is changed from a towering structure to a flat one, the hierarchy of the organization structure is reduced, and the bottom structure is mainly a team structure. A team structure at the bottom can facilitate communication and create an atmosphere of trust, while a superstructure is responsible for unified command. The rigid and flexible organizational structure is also conducive to the transmission of information. Front-line employees can quickly report what they have observed to their superiors during the epidemic, so that the superiors can take measures as soon as possible. For example, if the first patient with abnormal temperature is found, it can be reported in a timely manner, and the superior can take immediate action and make instructions to ensure the safety of employees and other passengers.

\section{CONCLUSION}

Organize art force of ascension can make rail transportation industry react more rapidly in the face of the outbreak, art force increase depends on tissue within the ascension of the individual art force, to keep awareness of environment change, should actively build trust in organization environment, construct the rigidflexible economic organization structure, moderate maintain organizational resources redundancy at the same time.

\section{REFERENCES}

[1] Mirza Waseem Hussain, Tabasum Mirza, Malik Mubasher Hassan. Impact of COVID-19 Pandemic 
on the Human Behavior[J]. International Journal of Education and Management Engineering, 2020, 10(8): 35-61, DOI: 10.5815/ijeme.2020.05.05

[2] Malik Mubasher Hassan, Tabasum Mirza and Mirza Waseem Hussain. A Critical Review by Teachers on the Online Teaching-Learning during the COVID-19[J]. International Journal of Education and Management Engineering, 2020, 10(8): 17-27, DOI: 10.5815/ijeme.2020.05.03

[3] Ali Tourani, Asadollah Shahbahrami, Alireza Akoushideh, Saeed Khazaee, Ching. Y Suen. Motion-based Vehicle Speed Measurement for Intelligent Transportation Systems[J]. International Journal of Image, Graphics and Signal Processing, 2019, 04(08): 42-54. DOI: 10.5815/ijigsp.2019. 04.04

[4] Petitti D B, Crooks V C, Buckwalter J G, et al. Blood pressure levels before dementia[J]. Archives of Neurology, 2005, 62(1): 112-116. DOI: 10. 1001/archneur. 62. 1. 112

[5] Egeland B, Carlson E, Sroufe L A. Resilience Process $[\mathrm{J}]$. Development \& Psychopathology, 1993, 5(04): $517 . \quad$ DOI: 10. $1017 / \mathrm{s} 0954579400006131$

[6] Doll L S, Bonzo S E, Sleet D A, et al. Building Resilience to Mass Trauma Events[M]. Springer US, 2007.

[7] Norris F. H., Stevens S. P., Pfefferbaum B., Wyche K. F., Pfferbaum, R. L. Community Resilience as a Metaphor, Set of Capacities, and Strategy for Disaster Readiness[J]. American Journal of Community Psychol, 2008, 41: 127-150. DOI: 10. 1007/s10464-007-9156-6

[8] Suryaningtyas D, Sudiro A, Eka T A, et al. Organizational Resilience and Organizational Performance: Examining the Mediating Roles of Resilient Leadership and Organizational Culture[J]. Academy of Strategic Management Journal, 2019, (18): 69-74.

[9] Gianluca, Pescaroli, Omar, et al. A Likert ScaleBased Model for Benchmarking Operational Capacity, Organizational Resilience, and Disaster Risk Reduction[J]. International Journal of Disaster Risk ence, 2020, (03): 158-163. DOI: 10. 1007/ s13753- 020-00276-9

[10] Balu, R. How to Bounce Back from Setbacks[J]. Fast Company, 2001, 45: 148-156.

[11] Gittell J H, Cameron K, Lim S, et al. Relationships, Layoffs, and Organizational Resilience: Airline Industry Responses to September $11[\mathrm{~J}]$. General
Information, 2006, 42(3): 300-329. DOI: 10. $1177 / 0021886306286466$

[12] Iii J F H, Orr J E. Assessing Behaviors that Create Resilient Organizations[J]. Employment Relations Today, 1997, 24(4): 29-39. DOI: 10. 1002/Ert. 3910240405

[13] Mallak, L. A. Putting Organizational Resilience to Work[J]. Industrial Management, 1998, 40(6): 8-13.

[14] Rudolph, J. W., \& Repenning, N. P. Disaster dynamics: Understanding the Role of Quantity in Organizational Collapse[J]. Administrative Science Quarterly, 2002, 47: 1-30. DOI: 10. 2307/3094889

[15] Coutu D L. How Resilience Works[J]. Harvard business review, 2002, 80(5): 46-50, 52, 55 passim. DOI: 10. 2469/faj. v58. n3. 2544

[16] Mei Ye, Ling Wenquan. New Progress in the Measurement of Organizational Resilience[J]. China Commerce and Trade, 2012(32): 246-248. "in Chinese". DOI: CNKI: SUN: ZGSM. 0. 2012 $32-125$

[17] Darkow P M. Beyond "Bouncing Back": Towards An Integral, Capability-Based Understanding of Organizational Resilience[J]. Journal of Contingencies and Crisis Management, 2019, 27. DOI: 10. 1111/1468-5973. 12246

[18] Freeman, Steven F. Moral Purpose and Organizational Resilience: Sandler O Neill \& Partners, L. P. in the Aftermath of September 11th[J]. Academy of Management Annual Meeting Proceedings, 2003 (1). DOI: 10. 5465/AMBPP. 2003. 13792457

[19] Lengnick-Hall C A, Beck T E. Adaptive Fit Versus Robust Transformation: How Organizations Respond to Environmental Change[J]. Journal of Management, 2005, 31(5): 738-757. DOI: 10. $1177 / 0149206305279367$

[20] Weick K E. Enacted Sense-Making in Crisis Situations[J]. Journal of Management Studies, 1988, 25(4): 305-317. DOI: 10. 1111/j. 1467-6486. 1988. tb00039. $\mathrm{x}$

[21] Kim K, Andrew S A, Jung K. Building Resilient Organizations: Organizational Resilience as a Network Outcome[J]. International Journal of Public Administration, 2020(2): 1-10. DOI: 10. 1080/01900692. 2020. 1758720

[22] Cynthia A. Lengnick-Hall and Tammy E. Beck and Mark L. Lengnick-Hall. Developing a capacity for organizational resilience through strategic human resource management[J]. Human Resource 
Management Review, 2011. DOI: 10. 1016/j. hrmr. 2010. 07. 001

[23] Angang H. Analyzing the Impacts of SARS Crisis on China's Economic Development[J]. Management Review, 2003, 15 (4): 3-5. "in Chinese"

[24] Robb, D. Building resilient organizations[J]. OD Practitioner, 2008, 32(3): 27-32.

[25] Tasic J, Amir S, Tan J, et al. A Multilevel Framework to Enhance Organizational Resilience[J]. Journal of Risk Research, 2019. DOI: 10. 1080/13669877. 2019. 1617340

[26] McCann, J. Organizational effectiveness: Changing concepts for changing environments[J]. Human Resource Planning, 2004: 27(1), 42-50.
[27] Vasconcelos I F F G D. Strategy, Organizational Change and Organizational Resilience[J]. Cad. ebape. br, 2017, 15. DOI: 10. 1590/1679395170357

[28] Luo Dongxia, Shi Kan, PENG Haotao. Research on organizational Resilience[J]. Human Resources Development in China, 2010, (08): 9-13. "in Chinese". DOI: https: //doi. org/10. 1007/ 10722167_15

[29] Luo Dongxia, Tian Yalin, Shi Kan. Research on organizational resilience -- Implications for Micro and Macro perspectives[J]. Journal of Economic Research, 2011(36): 208-212. . “in Chinese”. DOI: 10. 3969/j. issn. 1673-291X. 2011.36. 084 